\title{
Sob a superfície dos fatos, a complexidade de seu significado: o desafio da narrativa no Jornalismo Cultural
}

J. S. FARO - jsfaro@jsfaro.net

Universidade Metodista de São Paulo Possui graduação em História pela Universidade de São Paulo (1973), mestrado em Comunicação Social pela Universidade Metodista de São Paulo (1992) e doutorado em Ciências da Comunicação pela Universidade de São Paulo (1996). Atualmente é assistente doutor da Pontifícia Universidade Católica de São Paulo (PUC-SP) e professor adjunto da Universidade Metodista de São Paulo (UMESP). Atua nos cursos de graduação em jornalismo nas duas instituições e é docente do programa de pós-graduação em Comunicação da UMESP. Tem experiência na área de Comunicação, com ênfase em jornalismo; trabalha com projetos de pesquisa em história da comunicação, jornalismo investigativo, jornalismo cultural e ensino e pesquisa em comunicação.

\section{Resumo}

O trabalho opera com duas variáveis teóricas que se interrelacionam na análise dos desafios das narrativas produzidas pelo Jornalismo Cultural contemporâneo: a perda da centralidade da autoria da crítica em consequência da expansão do texto na internet e, em razão disso, a redução de referências intelectuais da sua audiência. A hipótese, a ser eventualmente comprovada em pesquisa empírica, é a de que a crítica cultural, por conta desse duplo processo, produza textos progressivamente mais herméticos e acadêmicos esvaziando-se de sua dimensão social junto ao público.

\section{Palavras-chave}

Jornalismo cultural, Narrativas, Internet

\begin{abstract}
The work operates on two theoretical variables that are interrelated challenges in the analysis of narratives produced by contemporary cultural journalism: the loss of centrality of the critique of authorship as a result of the expansion of the text on the Internet and because of this, the reduction of intellectual references of your audience. The event will eventually be proven in empirical research, is that cultural criticism, because of this double process, produce increasingly hermetic texts and academic emptying its social dimension to the public.
\end{abstract}

\section{Keywords}

Cultural journalism, Stories, Internet

Artigo recebido em 09/09/2011

Aprovado em 27/10/2011 


\section{O problema}

Num ensaio recente, publicado no suplemento Sabático do jornal O Estado de S. Paulo, Francisco Foot Hardman apontou a amplitude da crise vivida pela crítica cultural e literária no Brasil: "[ela] nada tem de singular, (...) é parte da crise geral de produção de conhecimento nas ciências humanas e, igualmente, da crise dos paradigmas modernos de invenção, representação e valor nos diferentes domínios do simbólico. Institucionalmente, a mercantilização acelerada do trabalho intelectual, processo antigo, trouxe aos espaços tradicionais de cultura humanista os ditames tecnicistas e burocráticos da produtividade serial e mecânica". É difícil apontar na sociedade contemporânea algum processo que esteja livre dessas variáveis indicadas por Hardman, tal é a sua abrangência e generalidade, mas pode-se afirmar que é na narrativa jornalística, em especial no âmbito do Jornalismo Cultural, que elas aparecem com mais força e intensidade.

Quais as razões que levam a isso? Ao contrário do jornalismo informativo, que se ocupa de boa parte da matéria bruta que é divulgada nos veículos, a crítica cultural, por sua natureza essencialmente analítica, que tem como foco de observação os processos estético-expressivos ou ético-políticos de que são feitas a maior parte de suas pautas (FARO, 2006), opera no âmbito de uma estrutura conceitual que vai além da lógica imanente dos fatos - tal como aparentemente trabalha a informação noticiosa, distinções um pouco à semelhança do que ocorre com as diferentes narrativas da História como relato e da Filosofia da História como interpretação ${ }^{i i}$. É possível afirmar que em razão dessas características ocorre no âmbito da crítica cultural uma inversão do fenômeno apontado por José Francisco Sanchez para quem “o discurso informativo tem finalidade exterior ou instrumental: ou seja, deve ter conhecimento de certos feitos e comunicar esses fatos a alguém (...) ao contrário do discurso literário que tem finalidade interna" (1992), isto é, no terreno das matérias culturais ganha relevância essa estruturação interior que aproxima a narrativa do jornalista de um exercício autoral que não se faz presente com as mesmas características com que aparece em outros gêneros.

Contribui para isso o fato de que o Jornalismo Cultural é um território por onde passam práticas discursivas oriundas de campos disciplinares diferentes, mas 
invariavelmente associados a objetivos que são compartilhados na sua configuração epistêmica. Dificilmente, nesse sentido, o especialista em quaisquer das áreas da cultura que são objeto de tratamento jornalístico deixa de produzir textos onde o universo conceitual se aproxima da carga semântica dos fatos sobre os quais informa e opina, tornando-se eventualmente referêcia performativa para o público (PRADO, 2005; GONÇALVES e FARO, 2008). Se isso é verdade, quer dizer, se há consistência na afirmação de que o profissional que trabalha na área do Jornalismo Cultural aproxima sua narrativa da dimensão estético-expressiva ou ético-política de sua pauta, então se justifica a hipótese com a qual trabalhamos: tanto quanto a História e a Crítica Literária, também esse gênero enfrenta o desafio de que fala Hardman - uma narrativa que se manifesta impotente para dar conta do esvaziamento oriundo "da crise dos paradigmas modernos de invenção, representação e valor”.

\section{A descentralidade da autoria na narrativa}

São dois os processos agônicos, simultâneos e convergentes através dos quais isso ocorre. O primeiro deles diz respeito à crescente descentralidade da autoria no terreno geral das narrativas, fato especialmente agravado no âmbito das práticas jornalísticas em consequência do impacto que a explosão da circulação virtual dos textos na internet continua tendo. Se é certo que, no painel mais amplo das formas de contar, o jornalismo caracterizou sua existência ao longo do tempo como um espaço marcado pelo princípio da autoria ${ }^{i i i}$, também é verdade que nos anos recentes esse pressuposto vem sendo sistematicamente abalado. Uma boa síntese desse processo é feita por Muniz Sodré para quem o "prestígio" do texto jornalístico deve-se à sua associação com o "primado do indivíduo como ser moral e autônomo", fato que dá a ele (ao texto) "um sentido de sacralidade (...) uma civilidade e uma transcendência que resistem a qualquer tentativa de redução a um plano meramente técnico" (SODRÉ, 2002). Essa herança clássica, cujo fundamento pressupõe uma "linearidade discursiva" indivisível em sua narratividade, caracteriza um regime de apreensão do real cuja marca é o núcleo individual em torno do qual giram as competências do conhecimento, da descrição e da interpretação dos fatos. Obviamente que o fenômeno não se restringe ao jornalismo, mas ao conjunto de construções institucionalizadas que marcou a origem da 
civilização burguesa. O jornalismo, no entanto, parece ser sua faceta mais evidente dada sua presença ostensiva no território das descrições do cotidiano e de todo o universo de temas que sintonizam o público com o universo de suas construções imaginárias.

Pois tem sido justamente aí, no abalo que provocam na "linearidade discursiva" própria de um regime autoral e indivisível, que as tecnologias virtuais contribuem para agravar a perda de substância narrativa do Jornalismo Cultural. Para o mesmo Sodré, a internet desautoriza o núcleo autoral clássico e, com isso, esvazia sua prática significante dos sinais internos e estruturantes que classicamente responderam por sua identidade.

Há sinais inconfundíveis de que essa fragilização da autoria provoca vagas sucessivas de perplexidade, como se os dispositivos de busca de tags na rede fossem os mesmos que a pesquisa de palavras-chave ou de descritores conceituais. Não é a mesma coisa, claro, mas os autores dos textos que povoam os suplementos da crítica cultural estão espantados com o que está acontecendo e lembram um pouco profissionais que integram carreiras onde a ordem reverencial do conhecimento disciplinava (e, eventualmente, ainda disciplina, mas com uma sensação de ameaça permanente) a sujeição à autoridade.

Agora mesmo, em meio a um conjunto de textos de extraordinária densidade sobre manifestações culturais dos jovens no século XXI, vem de Martín-Barbero a lembrança de que aquilo que ele chama de "des-ordenamento" cultural da contemporaneidade - posto que o termo desordem aqui indica uma outra ordem, diferente da disposição clássica e verticalizada da autoridade - reflete "a defasagem da escola em relação ao modelo social de comunicação que foi introduzido pelos meios audiovisuais e pelas 'novas' tecnologias (...)" (2008: 11), a exemplo do que ocorre em todos os sistemas cuja legitimação do reconhecimento residia na paternidade autoral ou na sua aceitação como fonte da sabedoria e da informação.

Um último exemplo ainda desse processo que afeta o Jornalismo Cultural e que tem na horizontalização da circulação de informações uma de suas raízes: a crise do ensaio. Na edição 59 da revista piauí - ela mesma uma publicação cujas interjeições de admiração que provoca revelam tratar-se de uma excepcionalidade no panorama geral da imprensa brasileira -, Pedro Meira Monteiro, professor de Literatura Brasileira em Princenton (EUA), a pretexto de uma resenha da obra de José Miguel Wisnik Veneno Remédio $^{\text {iv }}$ põe em dúvida a pertinência do gênero no panorama geral da crítica cultural e literária e indaga a respeito de sua sobrevivência exatamente pelo crescimento do volume de informações sobre a realidade (no caso específico citado pelo autor, a 
realidade brasileira): "Mas se esse conhecimento todo permite falar de forma mais nuançada sobre o Brasil, ele também inibe, lembrando que qualquer tentativa de fixar traços nacionais será um exercício impressionista que não resiste a uma análise criteriosa da sociedade e da história", para concluir:

O ensaio de interpretação nacional, contudo, não é e nunca foi o resultado do acúmulo de informações. (...) Seu horizonte é radicalmente outro, diferente daquilo que pode propor um estudo de cunho científico ou histórico. O horizonte do ensaio é de natureza ética, quase transcendente. Ele sonda a vocação da coletividade: indaga não apenas como se veio parar aqui, mas aonde se vai e, mais ainda, aonde se deve ir. (...) E o verdadeiro ensaísta é aquele que nomeia o destino, fazendo dele uma fábula na qual o leitor possa se reconhecer (MEIRA MONTEIRO, 2011).

\section{O estranhamento da audiência}

O outro processo que agrava o quadro descrito até aqui e que entendemos ampliar a crise vivida pelas narrativas do Jornalismo Cultural foi referido indiretamente por Luiz Costa Lima em entrevista concedida ao jornal Valor Econômico ${ }^{v}$ : embora com raízes que podem ser localizadas no final da 2a. guerra mundial, em 1945, como consequência da expansão dos meios de comunicação, as dificuldades da crítica cultural evidenciam hoje um paradoxo que parece enfeixar toda a dimensão do problema. "Através dos blogs e redes sociais não há critério algum de publicação", fato que leva Costa Lima a apontar o amadorismo como um dos males que fragiliza a esfera pública representada pelas publicações especializadas em cultura. “(...) a passagem do livro para a recepção multiplicada e multiplicante da internet se faz a partir de um foco não especializado" - afirma o professor da PUC-RJ, para acrescentar e concluir logo em seguida à indagação do repórter:

Isso significa que é favorecida a obra não especializada. Não é a partir do romance de terceira categoria que o romance vai se sustentar...

Quando a recepção especializada sai de cena, o que é, especificamente, que se perde?

É o pente-fino. Imagine o "Ulisses" de [James] Joyce. Estamos em 1922 e alguém me convida para escrever uma resenha, dizendo: "você tem 5 mil toques para escrever. Eu me recusaria. O que faria o resenhista de hoje? Uma pequena descrição do enredo, um histórico da obra, informações genéricas. O que se perdeu com isso? Ora, 
perdeu-se o próprio livro. O leitor fica sem saber por que esse livro teve a importância que não teve, por exemplo, W. Somerset Maugham, que era tão traduzido entre nós. Por que Joyce não é Paulo Coelho? A perda da crítica especializada leva as pessoas a comprar gato por lebrevi.

Esse segundo processo que, à semelhança do primeiro, chamamos de agônico manifesta-se, portanto, não propriamente em decorrência da pulverização dos elementos clássicos da autoria, entre eles a sua unicidade e lugar de enunciação, mas dos efeitos que ele tem no âmbito das referências da audiência dos textos. A pergunta, portanto, é incontornável: qual é a condição cultural da audiência no momento dessa crise sistematicamente alegada para a indicação da perda de significados das grandes narrativas?

A primeira reflexão vem da interpretação do texto de Raymond Williams, Culture is ordinary, feita por Maria Elisa Cevasco. Segundo a autora, a experiência do narrador está longe de ser exclusiva e individual, pois que ela é cultura e, como tal, partilhada pelo "modo de vida (...) de um tempo", "experiência ordinária (...) dada no nosso modo de vida" (2001: 45-47). Em Williams, ainda segundo Cevasco, essa formulação adquire o efeito de um deciframento, pois a definição dada pelo autor aponta para a construção de significados comuns: Usamos a palavra cultura nesses dois sentidos: para designar todo um
modo de vida - os significados comuns; e para designar as artes e o
aprendizado - os processos especiais de descoberta e esforço criativo.
Alguns escritores usam essa palavra para um ou para outro sentido,
mas insisto nos dois, e na importância de sua conjugação. As
perguntas que faço sobre nossa cultura são perguntas refentes aos
nossos propósitos gerais e comuns e, mesmo assim, são perguntas
sobre sentidos pessoais profundos. A cultura é de todos, em todas as
sociedades e em todos os modos de pensar $(2001: 49)^{\text {vii. }}$

A crítica posta nas páginas dos suplementos e dos segundos cadernos por profissionais da imprensa ou por autores legitimados no campo de sua especialidade e validados pelo próprio Jornalismo Cultural integra esse processo mais amplo descrito por Raymond Williams, mas faz mais que isso: partilha com seu público o poder cognitivo permitido pela análise das obras, fato que reproduz no âmbito da audiência os mesmos impasses narrativos apontados acima. O descentramento da autoria é também, em nossa opinião, a perda de referência do leitor, do espectador ou do ouvinte, ingrediente que desorganiza ainda mais a hierarquia textual que existia hegemonicamente antes da explosão da rede: onde havia um polo de argumentação em 
torno das características de qualquer tipo do fato cultural, agora proliferam mecanismos de busca cujo principal efeito parece ser o da percepção de uma autoria descaracterizada como tal, uma mera referência eventualmente recuperada mais por conta das normatizações acadêmicas e éticas do que pela reverência intelectual. Referência e reverência, aqui, não se confundem; representam posições distanciadas na relação da audiência com o texto: a primeira é normatizada e exigida até no plano legal, a segunda é resultado do prestígio e da aceitação socialmente legitimada.

Nesse sentido, o dinamismo da rede, a agilidade que ela permite nas várias possibilidades de navegação e a adaptabilidade a esse padrão perseguida pelos próprios sites, blogs e portais através da condensação do texto acabaram por colocar o Jornalismo Cultural em contradição com aqueles que seriam os fundamentos de sua existência e desenvolvimento, entre eles - além do problema relativo ao núcleo de sua autoria - o da extensão dos hábitos de leitura, mais do que os de sua intensidade ${ }^{\text {viii }}$, fato que levaria a audiência ao parâmetro fortemente quantitativo de consultas dispersivas e fragmentadas. Naturalmente, essa constatação não significa que se deduza que o gênero estaria vivendo etapa inexpressiva de atividade, mas que a área de sua abrangência passa por processo semelhante ao dos veículos tradicionais que abrigam os suplentos e cadernos onde a crítica cultural tradicionalmente encontra seu espaço físico e intelectual.

\section{Lamentos dos dois lados}

Essa perda de relevância social por si só já é um desafio para as narrativas, posto que seu acanhamento torna a produção do gênero mais hermética e acadêmica, eventualmente fazendo-o buscar refúgio em publicações voltadas para públicos reduzidos e de alta especialização ${ }^{\text {ix }}$. Ainda assim, quando permanecem em seus veículos de origem, as manifestações do Jornalismo Cultural tendem a refletir os mesmos sinais de estagnação de público que afeta as publicações tradicionais - lugar onde se reproduzem, mais que em outras mídias, as propostas mais antigas do gênero.

Referindo-se ao isolamento dos veículos tradicionais e suas consequências, depois de informar que a circulação média da Folha de S. Paulo foi, em 2009, de 295 mil exemplares/dia e caiu 5\%; do jornal $O$ Globo, de 257 mil e caiu 8,6\%; e do Estado de S.Paulo, de 213 mil e caiu 13,5\%, diz Venício A. Lima: 
Seu crescente "isolamento" [referindo-se aos grandes jornais] da maioria da população transformou-se em estratégia de sobrevivência no mercado. Esta é uma das razões porque seus "formadores de opinião" procuram agradar a um grupo cada vez mais reduzido de pessoas. O rádio deverá ficar cada vez mais local e regional. E a televisão onipresente, mas com a audiência em queda, parece se agarrar à espetacularização de toda a sua programação. E com isso, despenca sua credibilidade (LIMA, 2011).

Ora, esse é um processo cujo espectro de consequências em todas as narrativas é extraordinário, mas sem dúvida é naquelas com maior identificação de competência discursiva, de reconhecimento e de prestígio que ele é maior, e o Jornalismo Cultural se não é paradigmático nesse sentido, tem posição de relevo na própria interpretação do desenvolvimento do campo do Jornalismo. Para Habermas, por exemplo, trata-se de um gênero que se confunde com a história da imprensa exatamente pela natureza do vínculo que possibilita ao intelectual-jornalista (na perspectiva mais ampla da interpretação com a qual trabalhamos aqui) estabelecer com a esfera pública. Escrevendo sobre a tradição "engajada" dos intelectuais europeus depois de 1789, o autor alemão afirma que, embora eles tenham em mãos até o pós-guerra de 45 os instrumentos que lhes servem de "ressonância",

(...) parecem morrer sufocados diante do transbordamento desse elemento vivificador, como se ele lhes fosse administrado em overdose. A bênção parece transformar-se em maldição. As razões para isso me parecem ser uma informalização da esfera pública e uma indiferenciação dos correspondentes papéis.

A utilização da internet simultaneamente ampliou e fragmentou os nexos de comunicação. Por isso a internet produz por um lado um efeito subversivo em regimes que dispensam um tratamento autoritário à esfera pública. Por outro lado, a interligação em redes horizontais e informalizadas de comunicação enfraquece ao mesmo tempo as conquistas das esferas públicas tradicionais, pois estas enfeixam no âmbito de comunidades políticas a atenção de um público anônimo e disperso para informações selecionadas, de modo que os cidadãos podem ao mesmo tempo se ocupar dos mesmos temas e contributos criticamente filtrados. $O$ preço do aumento positivo do igualitarismo, com o qual a internet nos brinda, é a descentralização dos acessos a contribuições nãoredigidas. Nesse meio, as contribuições de intelectuais perdem a força necessária para formar um foco (...) (HABERMAS, 2006, grifos nossos).

"Nesse meio, as contribuições de intelectuais perdem a força para formar um foco", diz Habermas, constatação à qual acrescentaríamos que não a perdem senão 
como possibilidade narrativa, fato do qual decorre uma espécie de estranhamento mútuo entre esses dois polos que estão localizados no interior das práticas e dos usos do Jornalismo Cultural: os jornalistas e sua audiência. Os primeiros, atingidos no centro mesmo do processo de sua producão discursiva e eventualmente sob o impacto do processo de diluição das determinações de reconhecimento que orientavam tradicionalmente o público; a segunda, também atingida no núcleo de referências a que era levada por narrativas inconfundíveis nas suas características autorais.

O efeito dessa dimensão crítica vivida pelo Jornalismo Cultural, ainda que tais manifestações estejam sendo apresentadas aqui como construções teóricas que podem e devem - orientar um esquadrinhamento empírico de todo o processo, é um lamento generalizado de parte a parte: dos profissionais sobre o público que aparece "despreparado" e "inculto"; do público sobre os jornalistas, que emergem arrogantes e encastelados em suas ilhas conceituais inteligíveis só mesmo para aquela audiência tradicional e envelhecida que sempre foi sua, com ou sem internet. Como resultado, uma perda de relevância social da crítica. Talvez o trajeto das práticas discursivas tenha que ser refeito a partir do reconhecimento dessa nova realidade porque nada indica que as causas que lhe tem dado origem possam mudar. 


\section{Referências Bibliográficas}

FARO, J.S. (2006). Nem tudo que reluz é ouro: contribuição para uma reflexcão teórica sobre o jornalismo cultural. Comunicação \& Sociedade (METODISTA), São Bernardo do Campo - SP, ano 28, número 46. Universidade Metodista de São Paulo, 2006.

GONÇALVES, E. M. \& FARO, J.S. (2008) O performativo no jornalismo cultural: uma organização discursiva diferenciada. Revista Famecos (PUC-RS), Porto Alegre - RS, vol.1, 2008.

HABERMAS, Jürgen (2006). O caos da esfera pública. Publicado originalmente em Caderno Mais+. Folha de S. Paulo, 13 de agosto de 2006 (disponível em http://firgoa.usc.es/drupal/node/310640)

LIMA, Venício A. (2011). Grande mídia isolada no Brasil. Reproduzido em Fórum Nacional pela Redemocratização da Comunicação (http://www.fndc.org.br/internas.php? $\mathrm{p}=$ noticias\&cont key=491579), 2011.

MARTÍN-BARBERO, Jesús (2008). A mudança na percepção da juventude: sociabilidades, tecnicidades e subjetividades entre os jovens. In BORELLI, Silvia H. S. e FREIRE FILHO, João. Culturas juvenis no século XXI. São Paulo: Educ.

MEIRA MONTEIRO, Pedro (2011). Raízes do século XXI. In Revista Piauí, número 59, agosto de 2011 (disponível em http://migre.me/5B5t5).

PRADO, J. L.A. (2005) O leitor infiel diante dos mapas da mídia semanal performativa. Revista Fronteira (UNISINOS), São Leopoldo - RS, v. VII, n. 1, 2005.

SANCHEZ, José Francisco (1992). O jornalista como contador de histórias. Estudios de Periodistica: Ponencias do I Congresso de la SEP. Madri, Universidad Complutense, Faculdad de Ciencias de la Información.

SEVASCO, Maria Elisa (2001). Para ler Raymond Williams. São Paulo: Paz e Terra, 2001.

SODRÉ, Muniz (2002). Sobre o texto na rede cibernética. In: PERUZZO, Cicília \& ALMEIDA, Fernando F. de. A mídia impressa, o livro e as novas tecnologias. São Paulo: Intercom, Uniderp.

Este artigo e todo o conteúdo da Estudos em Jornalismo e Mídia estão disponíveis em http://www.periodicos.ufsc.br/index.php/jornalismo/index

Estudos em Jornalismo e Mídia está sob a Licença Creative Commons 
i Um ofício escrito no plural. Francisco Foot Hardmann. Sabático, O Estado de S. Paulo, edição de 27 de agosto de 2011.

ii A distinção entre as duas narrativas aparece no capítulo de autoria de Lloyd S. Kramer - Literatura, crítica e imaginação histórica: o desafio literário de Hayden White e Dominick Lacapra. In A nova história cultural. Lynn Hunt (organizadora). São Paulo: Martins Fontes, 1992.

iii Para uma síntese das referências bibliográficas que tratam do tema, ver o artigo O "eu" que reporta: autoria na revista Piauí (Valentini e Ijuim, Comunicação \& Sociedade, 55, Umesp, 2011).

iv José Miguel Wisnik. Veneno remédio: o futebol e o Brasil. São Paulo: Companhia das Letras, 2008.

${ }^{\vee}$ Por que James Joyce não é Paulo Coelho? Entrevista com Luiz Costa Lima, Valor Econômico, edição de 16 de fevereiro de 2011.

${ }^{\mathrm{vi}}$ Idem, ibidem.

vii Raymond Williams, Culture is Ordinary, 1958, p. 4, apud Maria Elisa Cevasco, op cit.

viii A questão foi lembrada por Gunter Axt, em matéria disponível em http://migre.me/5Cjuc, por ocasião do II Congresso de Jornalismo Cultural realizado em São Paulo em maio de 2010.

${ }^{\text {ix }}$ Veja-se, por exemplo, os casos das revistas Serrote, Dicta \& Contradicta e Cult cujo espaço de penetração junto ao público reduz-se hoje a diminutos pontos de venda localizados nos lugares de acesso de segmentos refinados da intelectualidade acadêmica e não-acadêmica, fato que contribuiu para que o conjunto de suas matérias tivesse como matriz uma produção textual elitizada e esotérica. 